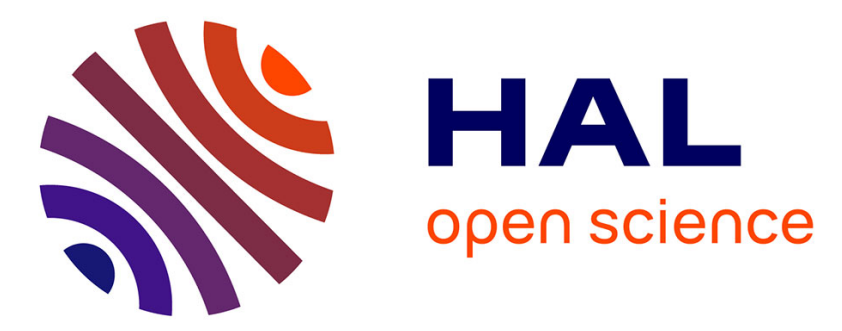

\title{
Temperature dependence of the resistivity and structure of liquid alkali metals
}

H. Minoo, C. Deutsch, J.P. Hansen

\section{To cite this version:}

H. Minoo, C. Deutsch, J.P. Hansen. Temperature dependence of the resistivity and structure of liquid alkali metals. Journal de Physique Lettres, 1977, 38 (9), pp.191-194. 10.1051/jphyslet:01977003809019100 . jpa-00231357

\section{HAL Id: jpa-00231357 https://hal.science/jpa-00231357}

Submitted on 1 Jan 1977

HAL is a multi-disciplinary open access archive for the deposit and dissemination of scientific research documents, whether they are published or not. The documents may come from teaching and research institutions in France or abroad, or from public or private research centers.
L'archive ouverte pluridisciplinaire HAL, est destinée au dépôt et à la diffusion de documents scientifiques de niveau recherche, publiés ou non, émanant des établissements d'enseignement et de recherche français ou étrangers, des laboratoires publics ou privés. 


\title{
TEMPERATURE DEPENDENCE OF THE RESISTIVITY AND STRUCTURE OF LIQUID ALKALI METALS
}

\author{
H. MINOO, C. DEUTSCH \\ Laboratoire de Physique des Plasmas (*), Université Paris XI, Bâtiment 212, \\ 91405 Orsay, France \\ and \\ J. P. HANSEN \\ Laboratoire de Physique Théorique des Liquides $\left(^{+}\right)$, Université Paris VI, \\ 4, place Jussieu, 75005 Paris, France
}

(Reçu le 17 février 1977, révisé le 1er avril 1977, accepté le 5 avril 1977)

\begin{abstract}
Résumé. - Un facteur de structure phénoménologique et simple $a(k)$ pour les métaux alcalins liquides est proposé, et utilisé pour calculer le coefficient de température de la résistivité à volume constant. Un excellent accord avec les résultats expérimentaux est obtenu.
\end{abstract}

\begin{abstract}
A simple phenomenological structure factor $a(k)$ for liquid alkali metals is proposed, and used to calculate the temperature coefficient of the resistivity at constant volume. Excellent agreement with experimental results is obtained.
\end{abstract}

In a previous paper [1] we considered electronic transport in dense fully-ionized hydrogen; here we extend our calculations to liquid alkali metals. This extension requires an appropriate choice of $a(k)$ and $U(k)$, where $a(k)$ is the static structure factor of the system and $U(k)$ is the Fourier transform of the screened pseudo-potential of a single ion (form factor).

The basic formula for the electrical resistivity, $\rho$, of liquid metals, in the framework of the nearly-freeelectron (NFE) model is [2]

$$
\rho=\frac{3 \pi}{\hbar e^{2}} \frac{\Omega}{v_{\mathrm{F}}^{2}} \int_{0}^{1}|U(k)|^{2} a(k) 4\left(\frac{k}{2 k_{\mathrm{F}}}\right)^{3} \mathrm{~d}\left(\frac{k}{2 k_{\mathrm{F}}}\right)
$$

where $k_{\mathrm{F}}$ and $v_{\mathrm{F}}$ are, respectively, the Fermi wavenumber and the Fermi velocity, and $\Omega$ is the atomic volume.

The temperature coefficient of $\rho$ at constant volume, $\alpha_{\Omega}$, is defined by :

$$
\alpha_{\Omega} \equiv \frac{T_{\mathbf{M}}}{\rho_{\mathbf{M}}}\left(\frac{\partial \rho}{\partial T}\right)_{\Omega}
$$

where $T_{\mathrm{M}}$ is the melting temperature and $\rho_{\mathrm{M}}$ is the electrical resistivity at $T_{\mathrm{M}}$. The evaluation of $\alpha_{\Omega}$ requires a knowledge of $[\partial a(k) / \partial T]_{\Omega}$. This quantity has not yet been measured experimentally, and has to be evaluated theoretically. The widely used PercusYevick hard-sphere model is unsatisfactory for the reasons given in reference [1]. Moreover, as was shown by Greenfield et al. [3], no combination of hard-sphere diameter and packing fraction can lead to quantitative agreement with the experimental data of the structure factor of liquid $\mathrm{Na}$ and $\mathrm{K}$.

Because of these difficulties the question of the temperature dependence of the resistivity [4] is left open $[5,6]$.

In the present work, we obtain a structure factor for liquid alkali metals by a normalized linear combination of $a(k)_{\mathrm{OCP}}$, and the correct thermodynamic limit of $a(k)$ at long-wavelength, $a(0) ; a(k)_{\mathrm{OCP}}$ is the structure factor, obtained from Monte-Carlo simulations, of the classical One-Component Plasma (OCP) [7]. Combining this structure factor with the empty-core model for the ionic pseudopotential, we obtain $\alpha_{\Omega}$ for liquid alkali metals in excellent agreement with experimental results. 
The structure factor $a(k)$ is related to the pair distribution function $g(r)$ by

$$
a(k)=a(0)+4 \pi n_{i} \int_{0}^{\infty}[g(r)-1]\left(\frac{\sin k r}{k r}-1\right) r^{2} \mathrm{~d} r
$$

where $a(0)$ is the long-wavelength limit of $a(k)$ and is defined by

$$
a(0)=1+4 \pi n_{i} \int_{0}^{\infty}[g(r)-1] r^{2} \mathrm{~d} r .
$$

In a first approximation we consider a liquid alkali metal as a set of ion cores and free degenerate valence electrons with equal number densities $\left(n_{i}=n_{\mathrm{e}}\right)$. Moreover, at the initial stage of this development, ion cores are regarded as point charges interacting through the repulsive coulomb potential and degenerate valence electrons are viewed as merely forming a uniform neutralizing background. This is essentially the basis of the OCP model. Brush, Sahlin, and Teller [8] have noted that the OCP is a reasonable model of liquid alkali metals, and later $\mathrm{Ng}$ [9] showed that certain equilibrium quantities, such as the melting temperature, the liquid structure factor, the specific heat at constant volume, and the entropy of liquid alkali metals near the triple point are correctly accounted for by the OCP model. As regards the structure factor of liquid alkali metals, the overall agreement between the experimental results and those obtained from the OCP is good except that $a(k)_{\text {OCP }}$ tends to zero as $k \rightarrow 0$ whereas the experimental curve does not (cf. Fig. 1).

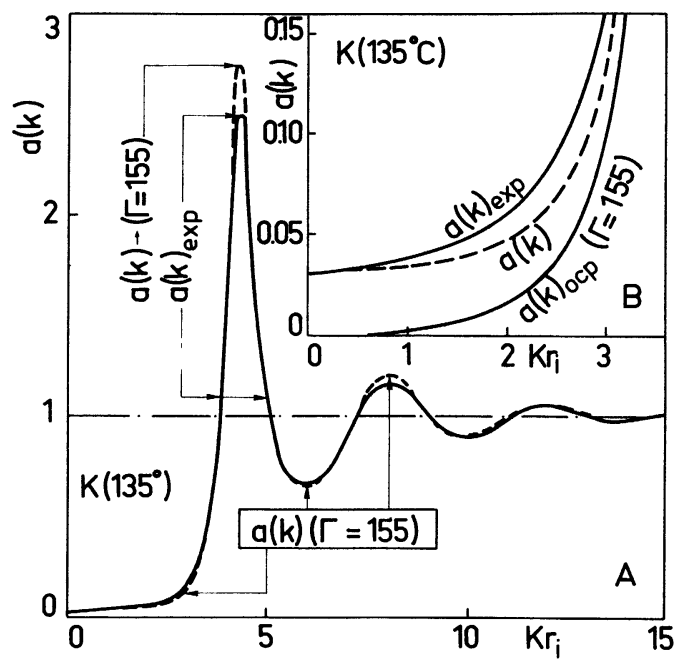

Fig. 1. - (A) Structure factor, $a(k)$, of liquid $\mathrm{K}$ at $135^{\circ} \mathrm{C} . a(k)_{\exp }$ : experimental results of Greenfield-Wellendorf-Wiser ; $a(k)_{\text {OCP }}$ : structure factor of the classical one-component plasma (OCP) : $a(k)$ : obtained from eq. (8) with $a(0)_{\exp }$ and $a(k)_{\text {ocp. }}$ (B) Longwavelength region of $a(k)$.
In fact the charge neutrality and perfect screening conditions imply that $[10]$ :

$$
a(x)_{\mathrm{OCP}} \simeq \alpha^{2} x^{2} / 3 \Gamma \text { as } x \rightarrow 0
$$

where $x=k / 2 k_{\mathrm{F}}, \alpha=(18 \pi Z)^{1 / 3}$ and $\Gamma$ is the single dimensionless parameter on which depend the equilibrium properties of the OCP :

$$
\Gamma=\beta(Z e)^{2} / r_{i}
$$

where $\beta=\left(k_{\mathrm{B}} T\right)^{-1}$.

However for real liquid metals the OCP model is too crude and one has to take into account the finitesize effect of ion cores and the polarization of the valence electrons by the ionic-charge distribution. These effects lead to a finite value of $a(0)$, which is related to the isothermal compressibility, $\chi_{\mathrm{T}}$, through the standard relation :

$$
a(0)=n_{i} \chi_{\mathrm{T}} / \beta
$$

This result can also be obtained in the framework of the two-component charged-particle model of a liquid metal [11].

Now, our basic assumption is that the structure factor of liquid alkali metals can be written as

$$
a(k)=f(k) a(0)+[1-h(k)] a(k)_{\mathrm{OCP}}
$$

where $a(0)$ is taken from experiment, $a(k)_{\mathrm{OCP}}$ is obtained from the Monte-Carlo simulation of the OCP [7], [12], and the functions $f(k)$ and $h(k)$ are chosen such that $a(k)$ tends to unity when $k \rightarrow \infty$ and fullfils the following sum rule [expressing that $g(0)=0]$ :

$$
\int_{0}^{\infty}[1-a(k)] k^{2} \mathrm{~d} k=2 \pi^{2} n_{i}
$$

In our calculation we chose

and

$$
\begin{aligned}
& f(k)=\exp -\left(k r_{i} / 5\right)^{4} \\
& h(k)=C \exp -\left[\left(k r_{i}-10\right) / 5\right]^{4},
\end{aligned}
$$

and we adjusted $C$ in such a way that the sum-rule, eq. (9), is obeyed by $a(k)$ as defined in eq. (8). The adjusted value of $C$, and also the maximum height of $h(k)$ are very small compared to unity and range between $10^{-4}$ and $10^{-3}$. Consequently in the interval $0 \leqslant k \leqslant 2 k_{\mathrm{F}}$ we have $f(k) \approx 1, h(k) \approx 0$ and also

$$
a(k) \approx a(0)+a(k)_{\mathrm{OCP}} .
$$

If we call $\rho_{1}$ and $\rho_{2}$ the resistivities obtained from eq. (8) and (10) respectively, then $\left(\rho_{1}-\rho_{2}\right) / \rho_{1}<10^{-4}$. This allows us to use eq. (10) safely for the purpose of resistivity calculations.

The structure factor $a(k)$ as obtained from eq. (8) is compared with the experimental results, $a(k)_{\text {exp }}$, of Greenfield et al. [13] for liquid $\mathrm{K}$ at $135^{\circ} \mathrm{C}$ and 
liquid $\mathrm{Na}$ at $200^{\circ} \mathrm{C}$ on figures 1 and 2 respectively. $\Gamma$ for $\mathrm{K}$ at $135^{\circ} \mathrm{C}$ is 153 and for $\mathrm{Na}$ at $200{ }^{\circ} \mathrm{C}$ is 163 . $a(k)_{\text {OCP }}$ at these $\Gamma$ are not available, and the closest values of $\Gamma$ for which $a(k)_{\mathrm{OCP}}$ is computed are 155 and 160.

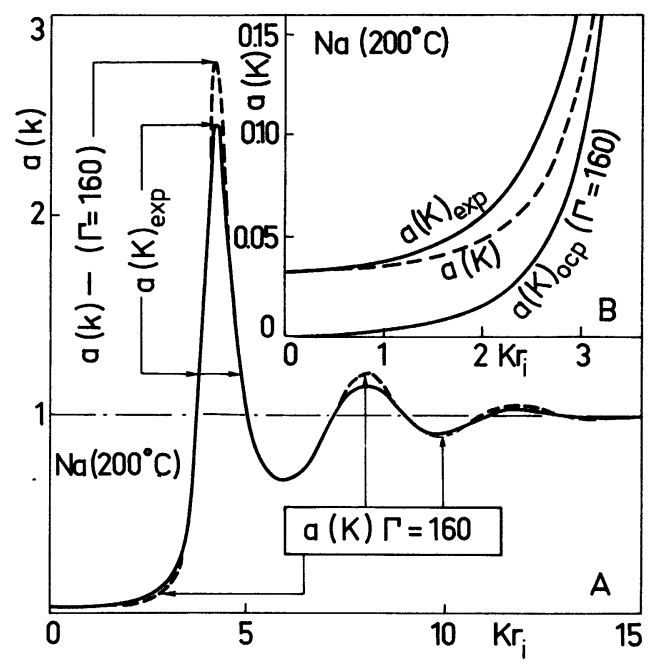

FIG. 2. - Structure factor of $\mathrm{Na}$ at $200{ }^{\circ} \mathrm{C}$.

It is seen that the agreement between the theoretical and the experimental curves is good except that the first and, to a lesser extent, the second peaks are somewhat overestimated. It is interesting to note that the theoretical and experimental curves are in phase, in contrast to the hard-sphere model [3].

In order to obtain $\alpha_{\Omega}$ as defined in eq. (2), the electrical resistivity, $\rho$, at constant volume, $\Omega_{\mathrm{M}}$, was computed from eq. (1). $\Omega_{\mathrm{M}}$ is the volume of liquid near melting. The structure factor $a(k)$ was derived from eq. (8) or (10) using $a(k)_{\text {ocP }}$ from references [7] and [11], and $a(0)_{\exp }$. The function $U(k)$ was obtained in the framework of the empty-core model [14]

$$
U(k)=-\frac{2}{3} \varepsilon_{\mathrm{F}} \lambda^{2} \cos (s x) /\left[x^{2}+\lambda^{2} f(x)\right]
$$

where $s=2 k_{\mathrm{F}} r_{\mathrm{c}}, \lambda^{2}=\left(\pi a_{0} k_{\mathrm{F}}\right)^{-1}, a_{0}$ is the first Bohr radius, $\varepsilon_{\mathrm{F}}$ is the Fermy energy, $f(x)$ is the Lindhard function

$$
f(x)=\frac{1}{2}+\frac{1-x^{2}}{4 x} \ln \left|\frac{1+x}{1-x}\right|
$$

and $r_{\mathrm{c}}$ is the empty-core radius. $r_{\mathrm{c}}$ was adjusted to reproduce the experimental resistivity at melting, $\rho_{\mathrm{M}}$. Figure 3 shows the comparison between experimental results and theoretical predictions of the resistivity of liquid alkali metals at constant volume $\Omega_{\mathrm{M}}$ and at different temperatures. Values of $\alpha_{\Omega}$ thus obtained theoretically are compared in table I (column 5) with experimental results (column 3). The experimental results are those measured by Endo [15] for $\mathrm{Na}$, $\mathrm{K}, \mathrm{Rb}$ and $\mathrm{Cs}$ and by Lien and Sivertsen [16] for $\mathrm{Na}$, $\mathrm{K}$ and $\mathrm{Rb}$. The maximum relative error of our results given in the table is $4 \times 10^{-3}$. If another potential

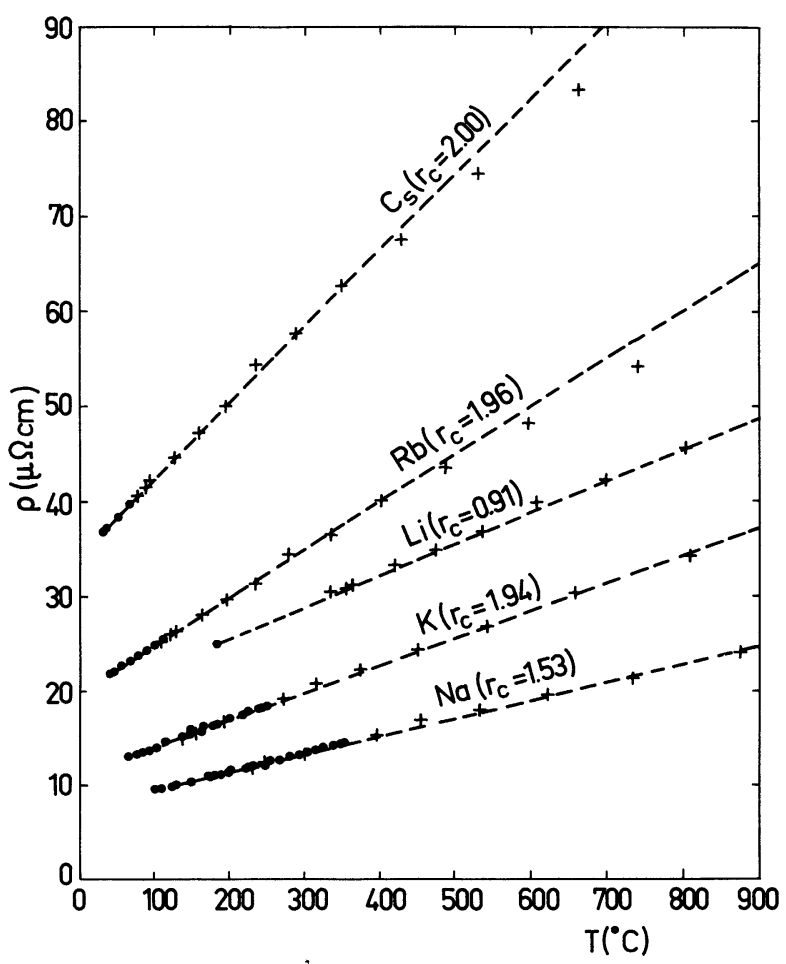

FIG. 3. - Electrical resistivity, $\rho$, of liquid alkali metals at constant volume, $\Omega_{\mathrm{M}}$, and at different temperatures, $T . \Omega_{\mathrm{M}}$ : liquid volume near the melting point $;(\ldots)$ : experimental results $;(+++)$ our results.

$U(k)$ is used, e.g. that proposed by Harrison [17], the calculated $\alpha_{\Omega}$ differs by less than $0.1 \%$.

The importance of the contribution of $a(0)$ in these calculations can be seen by putting $a(0)=0$ and $a(k)=a(k)_{\text {ocp }}$ in eq. (8). The results thus obtained for $\alpha_{\Omega}$ are reproduced in column 7 of the table. It is seen that in this case the agreement deteriorates appreciably.

Finally the apparently linear behaviour of $\rho(T)$ at low temperatures exhibited in figure 3 is qualitatively accounted for by the very weak $T$-dependence of $a(k)$, as can be seen through the inversion of the virial relationship

$$
\int \frac{4 \pi e^{2}}{k^{2}}[a(k)-1] \mathrm{d}^{3} \mathbf{k}=\frac{U}{N} \simeq-\frac{0.9 e^{2}}{r_{i}}, \quad \Gamma \gg 1
$$

where the right-hand-side is $T$-independent.

These results show that :

a) $a(k)$ as obtained from eq. (8) with $a(0)_{\text {exp }}$ reproduces the structure factor of liquid alkali metals reasonably well;

b) it is possible to obtain $\alpha_{\Omega}$ from Ziman's formula in quantitative agreement with the experimental data in the case of liquid alkali metals.

On the basis of these results we are now in a position to extend our previous calculations [1] to dense alkali metal vapors in the super-critical regime. 


\section{TABLE I}

Temperature coefficient of the resistivity at constant volume, $\alpha_{\Omega}$, and the electrical resistivity, $\rho_{\mathrm{M}}$, of liquid alkali metals near their melting. $r_{\mathrm{c}}$ is the empty-core radius in atomic units. $\left({ }^{(}\right)$Measured by Endo. $\left({ }^{b}\right)$ Measured by Lien and Sivertsen.

\begin{tabular}{|c|c|c|c|c|c|c|}
\hline & & ental results & {$[a(0)$} & ocP $]$ & & $\mathrm{CCP}]$ \\
\hline & $\begin{array}{c}\rho_{\mathrm{M}} \\
(\mu \Omega \mathrm{cm})\end{array}$ & $\alpha_{\Omega}$ & $\begin{array}{c}r_{\mathrm{c}} \\
(\mathrm{au})\end{array}$ & $\alpha_{\Omega}$ & $\begin{array}{c}r_{\mathrm{c}} \\
(\mathrm{au})\end{array}$ & $\alpha_{\Omega}$ \\
\hline & - & - & - & - & - & - \\
\hline $\mathrm{Li}$ & 25 & & 0.91 & 0.59 & 0.79 & 0.46 \\
\hline $\mathrm{Na}$ & 9.6 & $0.84\left(^{a}\right), 0.82\left(^{b}\right)$ & 1.53 & 0.79 & 1.39 & 0.57 \\
\hline $\mathrm{K}$ & 13 & $0.77\left(\left(^{a}, b\right)\right.$ & 1.94 & 0.76 & 1.78 & 0.61 \\
\hline $\mathrm{Rb}$ & 22 & $0.7\left(^{a}\right), 0.65\left(^{b}\right)$ & 1.96 & 0.7 & 1.80 & 0.57 \\
\hline Cs & 36 & $0.69\left(^{a}\right)$ & 2.00 & 0.66 & 1.84 & 0.54 \\
\hline
\end{tabular}

\section{References}

[1] Minoo, H., Deutsch, C. and Hansen, J. P., Phys. Rev. A 14 (1976) 840.

[2] Ziman, J. M., Phil. Mag. 6 (1961) 1013.

[3] Greenfield, A. J., WiSer, N., LeEnStra, M. R. and VAN DER LugT, W., Physica 59 (1972) 571.

[4] Greenfield, A. J., Phys. Rev. Lett. 16 (1966) 6.

[5] FABER, T. E., An Introduction to the Theory of Liquid Metals (Cambridge U.P., Cambridge) 1972.

[6] Ziman, J. M., The Properties of Liquid Metals, Proc. $2^{\text {nd }}$. Int. Conf. Tokyo, 1972 (Taylor and Francis LTD, London) 1973 , p. 13.

[7] Hansen, J. P., Phys. Rev. A 8 (1973) 3096.

[8] Brush, S. G., Sahlin, H. L. and Teller, E., J. Chem. Phys. 45 (1966) 2102.

[9] NG, K., preprint, University of Florida (1974).
[10] Stillinger, F. H. and Lovett, R., J. Chem. Phys. 49 (1968) 1991.

[11] Watabe, M. and Hasegawa, M., The Properties of Liquid Metals, Proc. $2^{\text {nd }}$ Int. Conf. Tokyo, 1972 (Taylor and Francis LTD, London) 1973, p. 133, see also DeUTSCH, C., J. Non-Cryst. Solids 8-10 (1972) 713.

[12] Galam, S. and Hansen, J. P., Phys. Rev. 14 (1976) 816.

[13] Greenfield, A. J., Wellendorf, J. and Wiser, N., Phys. Rev. A 4 (1971) 1607.

[14] AshCroft, N. W., J. Phys. C (Proc. Phys. Soc.) 1 (1968) 232.

[15] ENDo, H., Phil. Mag. 8 (1963) 1403.

[16] Lien, S. Y. and Sivertsen, J. M., Phil. Mag., 20 (1969) 759.

[17] Harrison, W. A., Pseudopotentials in the theory of metals (Benjamin, New York) 1966. 